\title{
Effect of Microstructure on the Corrosion Resistance of the AE42 Magnesium Alloy Processed by Rotary Swaging
}

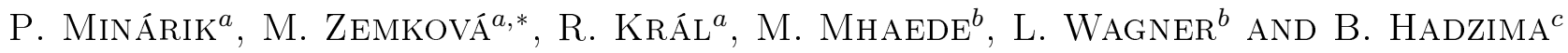 \\ ${ }^{a}$ Charles University in Prague, Department of Physics of Materials, Prague, Czech Republic \\ ${ }^{b}$ Institute of Materials Science and Technology, Clausthal Univeristy of Technology, Clausthal-Zellerfeld, Germany \\ ${ }^{c}$ Research Center of the University of Žilina, Žilina, Slovak Republic \\ and Faculty of Mechanical Engineering, University of Žilina, Žilina, Slovak Republic
}

\begin{abstract}
Microstructure and corrosion resistance of the AE42 commercial alloy processed by extrusion and rotary swaging were investigated. Microstructure characterization showed an increasing volume fraction of the refined grains with increasing stage of swaging processing. However, their presence was limited solely to the peripheral ring of $\approx 1 \mathrm{~mm}$ in all studied conditions of swaged material. Corrosion resistance investigation showed continuous decrease of polarization resistance that was attributed to the grain refinement and insufficient homogenization of the alloying elements during the swaging process.
\end{abstract}

DOI: 10.12693 /APhysPolA.128.805

PACS: 81.05.-t, 82.45.Bb

\section{Introduction}

Rotary swaging (RS) is a special type of radial hammer forging process that is a plastic forming technology in the manufacturing of metal rods and tubes. In the recent years, this processing technology was utilized to produce a variety of materials based on $\mathrm{Al}, \mathrm{Cu}, \mathrm{Fe}, \mathrm{Ti}[1-5]$. However, this technique was not extensively used for $\mathrm{Mg}$ and its alloys. The current results on Mg showed substantial grain refinement of the final material when compared to the as-cast condition [6].

Magnesium and its alloys have lately been in the focus of researchers due to their superior properties, however insufficient corrosion resistance is still one of the major drawbacks that need to be addressed. In the recent years, a positive effect of the grain refinement on the corrosion resistance was shown that was achieved mainly by equal channel angular pressure (ECAP) [7, 8]. It was shown that grain refinement due to the RS could lead to comparable grain size as achieved by ECAP [9]. This technique is very interesting as it enables much faster throughput and lower operating costs than other severe plastic deformation methods. The results on aluminum alloy showed increased corrosion resistance after RS [1]; however, there are no results regarding corrosion resistance of magnesium processed similarly yet.

Current investigations were undertaken to study the effect of the RS processing on the microstructure evolution of the commercial AE42 magnesium alloy. Afterwards, corrosion resistance evolution will be characterized and discussed.

${ }^{*}$ corresponding author; e-mail: Maria.Zemkova@mff.cuni.cz

\section{Material and experimental methods}

Material used in this investigation was the commercial magnesium alloy AE42 (Mg-4wt\% $\mathrm{Al}-2 \mathrm{wt} \%$ rare earths mischmetal). The as-received ingots were extruded at $T=350{ }^{\circ} \mathrm{C}$ with an extrusion ratio of $\mathrm{ER}=22$. The extruded rods were afterwards swaged using a 4-hammer rotary swaging system. swaging was performed using a set of molds to reduce the diameter of the rods from $15.5 \mathrm{~mm}$ (as-extruded) to $7.5 \mathrm{~mm}$ in five successive steps, as shown in the diagram:

$$
\begin{aligned}
& 15.5 \mathrm{~mm}(\mathrm{E}) \rightarrow 15 \mathrm{~mm} \rightarrow 12 \mathrm{~mm}(\mathrm{RS} 1) \rightarrow \\
& 10.5 \mathrm{~mm} \rightarrow 9 \mathrm{~mm}(\mathrm{RS} 2) \rightarrow 7.5 \mathrm{~mm}(\mathrm{RS} 3) .
\end{aligned}
$$

Four conditions of processed material were chosen for investigation (E, RS1, RS2, RS3). The processing temperature for all swaging steps was $250^{\circ} \mathrm{C}$ with an intermediate 10 min reheating to the temperature.

The microstructure observation was performed using a light optical microscope (LM) and a scanning electron microscope (SEM) equipped with EBSD camera. The samples for LM were mechanically polished up to $0.25 \mu \mathrm{m}$ diamond paste and afterwards chemically etched. Samples for SEM were mechanically polished up to $0.25 \mu \mathrm{m}$ diamond paste and afterwards electrochemically polished in order to obtain high quality surface. EBSD mapping was performed at least on an area of $250 \times 250 \mu \mathrm{m}^{2}$ in all studied samples to investigate the homogeneity of the microstructure. All micrographs were taken in the plane perpendicular to the processing direction, if not otherwise specified in text.

Corrosion resistance of the studied samples was investigated by linear polarization tests in $0.1 \mathrm{M} \mathrm{NaCl}$ solution at the room temperature. The tests were conducted using the potentiostat AUTOLAB128N and three-electrode setup. The characteristics were measured in the potential range from $-150 \mathrm{mV}$ to $200 \mathrm{mV}$ with respect to the open 
circuit potential (OCP) and constant rate of $1 \mathrm{mV} \mathrm{s}^{-1}$ after $5 \mathrm{~min}$ of stabilization. Additional rotation of $300 \mathrm{rpm}$ was introduced to the sample to provide better homogeneity of the measurement.

\section{Results and discussion}

The evolution of the microstructure due to the processing was analyzed by LM and EBSD. The microstructure of the as-extruded material was formed by bimodal distribution of the grain size, as depicted in Fig. 1a. The small grains had a diameter of $\approx 5 \mu \mathrm{m}$ while the large grains had a diameter of $\approx 40 \mu \mathrm{m}$. Continuous dynamic recrystallization (c-DRX) during the swaging process led to comparable microstructure of all studied conditions only with decreasing diameter of the rods, according to the diagram (1). The central area of the rods was formed by uniform distribution of fine grains of $\approx 5 \mu \mathrm{m}$ in diameter in all studied conditions. Resulting EBSD micrographs are presented as Fig. 1b-d. The comparable microstructure of the central part documents well the grain size distribution curves shown in Fig. 2.
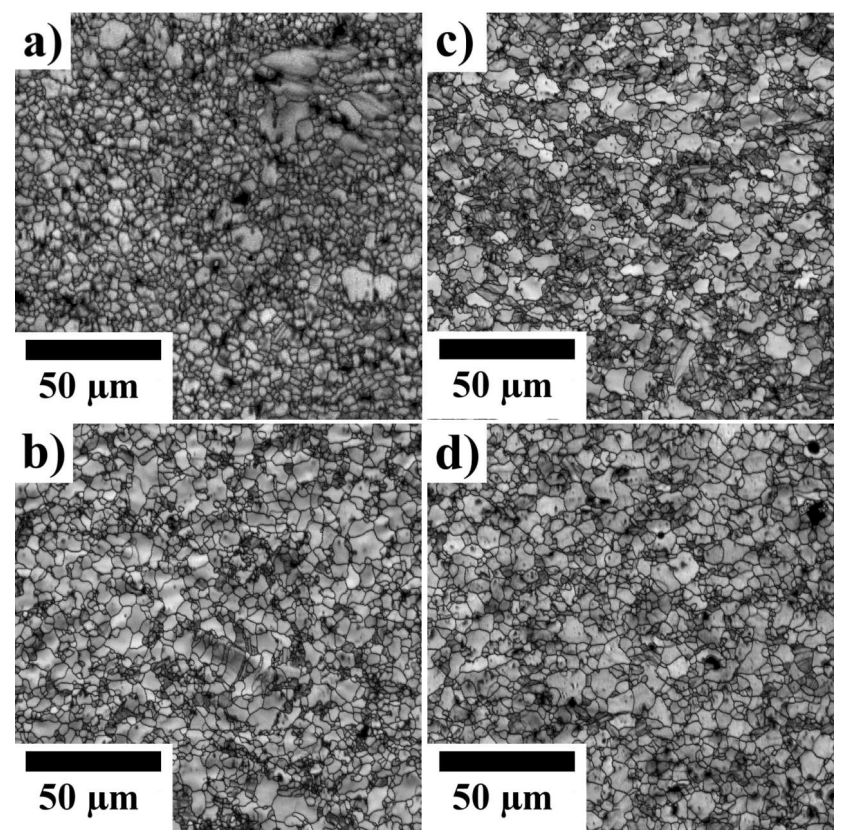

Fig. 1. EBSD micrographs of various conditions of AE42 (a) as-extruded, (b) RS1, (c) RS2, and (d) RS3.

However, as the plastic deformation was introduced to the material from the outside during the swaging process, microstructure was not homogeneous through the whole cross-section of the rods. The processing led to substantial grain refinement in the peripheral area of the processed rods. The average grain size was $\approx 2 \mu \mathrm{m}$ in this area compared to $\approx 5 \mu \mathrm{m}$ in the central part of the processed rods. This inhomogeneity is depicted well in Fig. 3. It should be noted that the refined grains areas were limited only to the peripheral ring of the crosssection of $\approx 1 \mathrm{~mm}$ in thickness in all swaged samples. Because of the change of the rods diameter, the volume fraction of the small grains increased from $30 \%$ in RS1

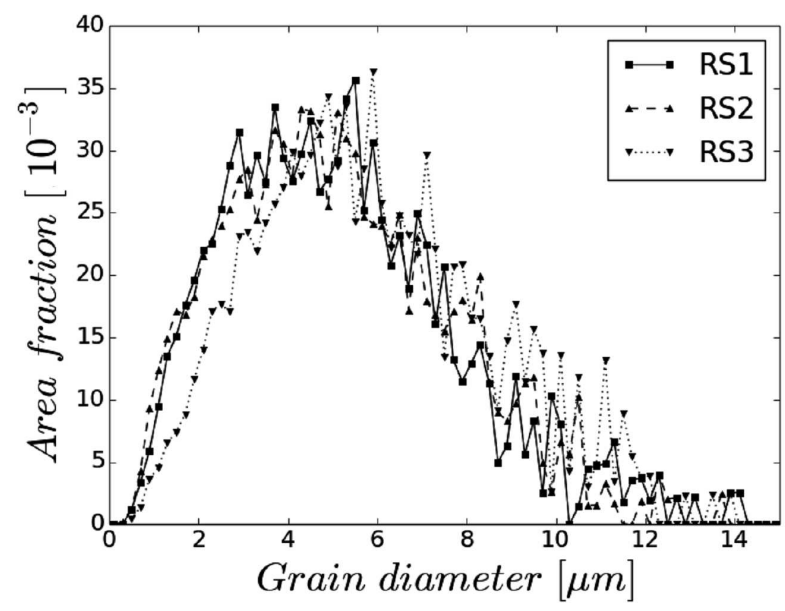

Fig. 2. Grain size distributions of swaged AE42.

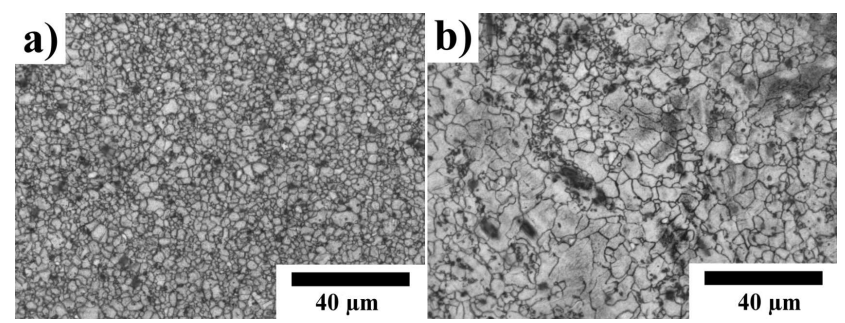

Fig. 3. LM micrographs of RS1 sample cross-section: (a) peripheral area and (b) central area.

condition to $40 \%$ and $46 \%$ in $\mathrm{RS} 2$ and $\mathrm{RS} 3$ condition, respectively.

The c-DRX during the swaging resulted only in limited grain refinement in the central area of the rods. A continuous decrease of the grain size was observed with increasing stage of the processing of pure Mg by RS [6]. However, in this study, the as-casted condition was used as the initial material of the processing. In our study, the microstructure was severely refined by extrusion in the beginning. Similar behavior was found in the ZK60 alloy, where a bimodal microstructure with small grains of 1-2 $\mu \mathrm{m}$ was achieved by extrusion [9]. Subsequent swaging resulted only in the unification of the grain size distribution similar to this study. Therefore, in this alloy, the grain refinement limit was most probably achieved within the used temperature range during RS.

Processing by rotary swaging had substantial effect on the corrosion resistance of the investigated alloy. The results showed continuous decrease of the corrosion resistance with increasing stage of the processing.

TABLE

Polarization resistance determined from Fig. 4a.

\begin{tabular}{c|c}
\hline \hline condition & {$\left[\Omega \mathrm{cm}^{2}\right]$} \\
\hline E & $165 \pm 1$ \\
RS1 & $159 \pm 1$ \\
RS2 & $156 \pm 1$ \\
RS3 & $146 \pm 1$
\end{tabular}




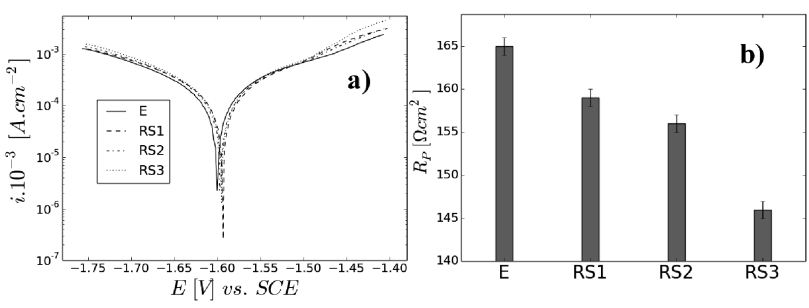

Fig. 4. a) Evans diagrams of the AE42, (b) polarization resistance $R_{P}$ as a function processing condition, determined from (a).

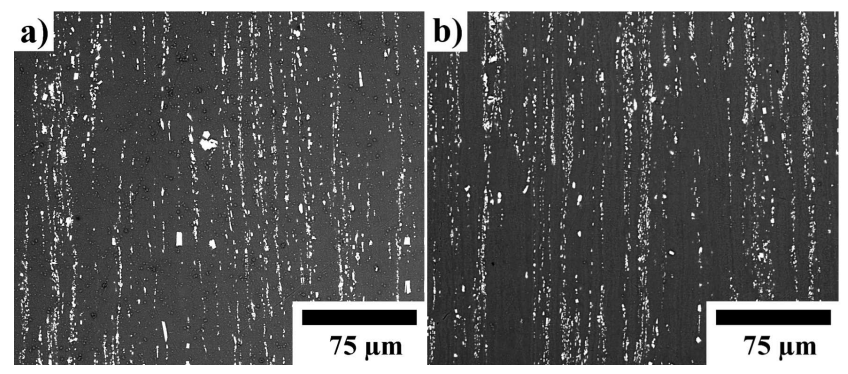

Fig. 5. Distribution of secondary phase particles in a) $\mathrm{E}$ and $\mathrm{b}$ ) RS3. (SEM, plane parallel to the processing direction).

The measured data sets are presented in the form of the Evans diagrams in Fig. 4a. The evaluated values of the polarization resistance are presented in the Table and graphically displayed as Fig. $4 \mathrm{~b}$.

The decrease of the corrosion resistance is attributed to the grain refinement due to the increase of the volume fraction of small grains. The increase of the initial corrosion attack in the refined condition is due to the increase of the surface fraction of crystalline lattice defects, where the corrosion process primarily occurs. In our previous work, an increase of the corrosion resistance was shown in the investigated alloy processed by ECAP [10]. This increase was attributed to the combined effect of the lower grain size and better distribution of the alloying elements localized in the secondary particles due to the processing. Therefore, the corrosion layer that formed on the surface of the ECAPed sample was more stable and more protective against further corrosion process. In case of the material processed by RS, no change in the distribution of secondary particles was observed, as depicted in Fig. 5 . These results support previous conclusions about the importance of the redistribution of alloying elements during the processing.

\section{Conclusions}

The microstructure and corrosion resistance of the AE42 commercial alloy processed by extrusion and rotary swaging were investigated. The following conclusions may be drawn from this study:
- The microstructure investigation showed comparable microstructure in all swaged samples as a result of continuous dynamic recrystallization during the process.

- In all studied conditions of the swaged material, a peripheral ring of the fine grains was found as a result of the processing. The volume fraction of this ring gradually increased, which led to the grain refinement of the material.

- The corrosion resistance decreased with the increasing stage of the swaging processing.

- The decrease of the corrosion resistance was attributed to the higher surface fraction of the crystalline lattice defects and insufficient redistribution of the alloying elements rich secondary particles.

\section{Acknowledgments}

The present work is a part of the Czech Grant Agency project 14-13415S. B. Hadzima acknowledges the financial support from the European Regional Development Fund and the Slovak state budget under the project with the ITMS code 26220220183. Some experimental work has been performed in the frame of bilateral $\mathrm{CZ} / \mathrm{SK}$ project 7AMB14SK116 / SK-CZ-2013/0112.

\section{References}

[1] M. Abdulstaar, M. Mhaede, L. Wagner, M. Wollmann, Mater. Des. 57, 325 (2014).

[2] W. Pachla, M. Kulczyk, S. Przybysz, J. Skiba, K. Wojciechowski, M. Przybysz, K. Topolski, A. Sobolewski, M. Charkiewicz, J. Mater. Process. Technol. 221, 255 (2015).

[3] N. Durlu, N.K. Çalişkan, Ş. Bor, Int. J. Refract. Met. Hard Mater. 42, 126 (2014).

[4] B. Katavić, Z. Odanović, M. Burzić, Mater. Sci. Eng. A 492, 337 (2008).

[5] M.A. Abdulstaar, E.A. El-Danaf, N.S. Waluyo, L. Wagner, Mater. Sci. Eng. A 565, 351 (2013).

[6] W.M. Gan, Y.D. Huang, R. Wang, G.F. Wang, A. Srinivasan, H.-G. Brokmeier, N. Schell, K.U. Kainer, N. Hort, Mater. Des. 63, 83 (2014).

[7] J. Jiang, A. Ma, N. Saito, Z. Shen, D. Song, F. Lu, Y. Nishida, D. Yang, P. Lin, J. Rare Earths 27, 848 (2009).

[8] B. Hadzima, M. Janecek, M. Bukovina, R. Kral, Int. J. Mater. Res. 100, 1213 (2009).

[9] M.Z. Oo, M. Janeček, R. Kral, L. Wagner, Acta Phys. Pol. A 122, 606 (2012).

[10] P. Minárik, R. Král, M. Janeček, Appl. Surf. Sci. 281, 44 (2013). 